\title{
La datación de la ascensión al trono de Esparta de Agesilao II y la cronología de la dinastía XXX egipcia
}

\author{
José PASCUAL ${ }^{1}$ \\ Universidad Autónoma de Madrid \\ jose.pascual@uam.es
}

\section{RESUMEN}

Este trabajo trata de fijar la fecha de la ascensión al trono de Esparta de Agesilao II, uno de los más célebres e importantes reyes que tuviera el Estado lacedemonio, así como la extensión total de su reinado sobre la base de las noticias recogidas en los autores grecolatinos y, especialmente, a través de las fuentes egipcias y de lo que conocemos de la cronología de la XXX dinastía de faraones egipcios. La fecha de su ascenso al trono, que fijamos en 399, año espartano 400/399, nos permite asimismo establecer de una manera más precisa la cronología de los acontecimientos que tuvieron lugar en Grecia y en el Mediterráneo oriental entre los años 403 y 396.

Palabras clave: Historia Antigua. Grecia. 403-396 a.C. Esparta. Agesilao II.

\section{The dating of the ascension of Agesilaus II to the throne of Sparta and the chronology of the $30^{\text {th }}$ Egyptian Dynasty}

\begin{abstract}
This paper tries to date the ascension to the Spartan throne of Agesilaus II, one of the most famous and important kings of the Lacedaemonian State, as well as the length of its reign based on both Greek and Latin ancient writers and, specifically, through the Egyptian sources and on what we already know on the chronology of the Egyptian Pharaons of the $30^{\text {th }}$ dynasty. The date on which Agesilaus became king in the Julian Year 399, the Spartan Year 400/399, likewise permits us to establish a more precise chronology of the events that took place in Greece and in the East Mediterranean between 403 and 396 B.C.
\end{abstract}

Key words: Ancient History. Greece. 403-396 B.C. Sparta. Agesilaus II.

Sumario: 1. Objetivos y presupuestos metodológicos. 2. La extensión de los reinados de Agis II y Agesilao II. 3. La XXX dinastía egipcia. 4. Conclusiones. El ascenso al trono de Agesilao II de Esparta y la cronología de los años 403 a 396 a.C.

1 Este trabajo se ha realizado en el marco de los proyectos de investigación HAR2008-04081/HIST y HAR2011-25443 financiados por el Ministerio de Ciencia e Innovación. 


\section{OBJETIVOS Y SUPUESTOS METODOLÓGICOS}

En los albores del siglo IV tuvo lugar el ascenso al trono de Esparta de Agesilao II, de la dinastía de los Euripóntidas, indudablemente uno de los reyes más afamados y destacados de toda la historia espartana, ${ }^{2}$ bajo cuya influencia habría de vivir no sólo Esparta, sino también el conjunto de la Hélade a lo largo de gran parte de la primera mitad de dicha centuria, especialmente en la generación que media entre el final de la Guerra del Peloponeso y la batalla de Leuctra (404-371), época en la que convenimos en situar, con razón, la hegemonía espartana y la del mayor apogeo de la potencia lacedemonia, que el propio rey en buena medida ejemplificó y modeló.

Debido a la importancia que posee la figura de Agesilao para la historia de Grecia, todo lo relativo a su vida y reinado cobran una transcendencia extraordinaria. En este sentido, la fecha de su elevación al trono supone, a nuestro juicio, uno de los sucesos fundamentales para datar y ordenar, y, por lo tanto, llegar a interpretar de una manera más adecuada, los acontecimientos que atañen a Grecia y al Mediterráneo oriental en los años que median entre el restablecimiento de la democracia en Atenas y el comienzo de la Guerra de Corinto, esto es, entre 403 y 396.

Los problemas para datar el ascenso al trono de Agesilao y los sucesos que ocupan los años 403 a 396, nacen esencialmente de las diferencias, ya cronológicas, ya de contenido, que presentan los relatos de nuestras dos fuentes principales de información, Jenofonte y Diodoro. ${ }^{3}$ Para enfrentarse a los múltiples problemas que plantean ambos testimonios, la historiografía ha procedido en ocasiones a analizar pormenorizadamente los relatos de los autores griegos y habitualmente ha narrado globalmente todos estos acontecimientos, insertando en dicha reconstrucción el ascenso al trono de Agesilao. ${ }^{4}$

Nosotros adoptaremos hasta cierto punto una orientación metodológica diferente, basada en cuatro supuestos principales:

a) La importancia, ya enunciada, de la ascensión al trono de Agesilao para datar los acontecimientos que median entre los años 403 a 396.

b) Aquello que podemos conocer acerca del funcionamiento del calendario lacedemonio.

c) La forma habitual de contabilizar los años de los reinados de los faraones egipcios.

d) La cronología de la XXX dinastía egipcia, que es coetánea de la última parte del reinado de Agesilao II.

2 Cf. Plu. Ages. 40.2; Sмith 1953/54, 274; Thomas 1974, 262-263. La bibliografía sobre Agesilao es muy extensa, baste citar aquí, con las referencias incluidas en cada obra, DeVoto 1982; CARTLEDGe 1987; HAmiLton 1991 y SHIPLEY 1997. Sobre Esparta en general uid. ForNIS 2003. Acerca de la hegemonía espartana cf. BucKLER 2003; PASCUAL 1997, 17-38. Sobre la realeza espartana: CARLIER 1984, 240-324.

3 X. Hell. 3.1.1-3.11; Diod. 14.17.1-12, 19.1-39.6, 79.1.

4 Vid. p.e. BuCKLER 2003, y Hamilton 1982. 
Así pues, en sentido inverso al tradicional, discutiremos en primer lugar la fecha de la subida al trono de Agesilao para elaborar, posteriormente y a partir de ella, un esquema cronológico en el que se dispongan el resto de los sucesos acaecidos en el período. Esto equivale a sostener que la ascensión al trono de Agesilao puede aproximarnos a la datación del resto de los acontecimientos y no al contrario. La razón es muy sencilla: sobre la vida de Agesilao disponemos de un buen número de noticias susceptibles de ser aprovechadas desde el punto de vista cronológico.

Una breve exposición de estos supuestos de partida nos ayudará a comprender el desarrollo de este trabajo. Ciertamente no podemos (ni debemos) obviar los relatos que conservamos de los diferentes autores antiguos y de ello nos ocuparemos, como se verá, en la primera parte de nuestro trabajo, pero no nos plantearemos una discusión detallada de los testimonios y las controversias generadas por autores como Jenofonte, Diodoro o Plutarco porque creemos que las noticias que nos transmiten todos ellos no son determinantes. Así, por tomar un ejemplo, aludiremos sólo de una manera incidental a los relatos de Jenofonte y Diodoro ${ }^{5}$ sobre la guerra que los lacedemonios emprendieron contra la Élide, que se ha fechado diversamente entre 402 y 399 y que ha sido tomada como base esencial para datar el ascenso al trono de Agesilao. ${ }^{6}$ Por el contrario, a diferencia de otros autores, tanto en este caso cuanto que en el conjunto de las fuentes griegas, nosotros consideramos que los resultados que arroja un análisis pormenorizado de los testimonios transmitidos por estos escritores griegos son poco concluyentes.

El año civil espartano comenzaba entre el solsticio de verano y el equinoccio de otoño, quizá en la primera o segunda neomenia anterior al equinoccio otoñal, esto es, habitualmente entre agosto y septiembre, según se tratara de un año normal de doce meses o de uno de trece al que se le hubiera introducido un mes intercalar. ${ }^{7}$ Parece probable también que el año lacedemonio diera principio con

5 La guerra de la Élide constituye, a un tiempo, un ejemplo de las dificultades a las que nos enfrentamos y de resultados poco concluyentes. Según Jenofonte (Hell.3.2.21-31), la guerra entre Élide y Esparta se alargó durante tres años. Los dos primeros años estuvieron ocupados por dos expediciones lacedemonias, al mando del rey Agis y, a comienzos de la primavera del tercer año, los eleos pidieron la paz. Si como él mismo dice, la guerra es sincrónica con el mando de Dercílidas en Asia (X. Hell. 3.2.21, cf. infra), entonces la primera campaña contra la Élide tendría lugar en el verano de 399, la segunda invasión ocuparía el año 398 y los eleos pedirían la paz en la primavera de 397. De este modo, la muerte de Agis caería en el verano de 397 y la sucesión al trono en el verano-otoño de 397. La narración de Diodoro (14.17.4-12) es muy diferente. Así, la guerra contra la Élide comenzaría en el arcontado de Mición (402/1). El conflicto se prolongaría únicamente durante dos años y hubo una sola expedición espartana, encabezada en este caso por el rey Pausanias, y que tendría lugar en 402 o en 401. Al año siguiente, el segundo del conflicto, en el arcontado de Cenéneto (401/0) los eleos pedirían la paz. Para este conflicto y su cronología pueden consultarse UnDERHILl 1893, Unz 1986 y FALKNER 1996.

6 Hamilton 1982, 286-290.

7 Beloch $G G$ II $^{2}, 2$ 2, 1931, 271-272; Pareti 1961 [1909/1910], 213; Trümpy 1997, 140. No podemos incluir aquí toda la evidencia a nuestra disposición y debemos contentarnos con señalar dos ejemplos. Jenofonte (Hell. 2.3.4) menciona el eclipse del 3 de septiembre de 404, después del cual Lisandro regresó a Esparta al terminar el verano (X. Hell. 2.3.9), verosímilmente antes del comienzo del nuevo año espartano. Asimismo, los Diez Mil se entrevistaron a su regreso en Bizancio, hacia septiembre de 400, con el navarco lacedemonio Anaxibio, que está esperando ser relevado por la llegada de Polo, el navarco del año siguiente (X. Anab. 7.2.5-7; Diod. 14.30.4 y para todo el recorrido entre Cunaxa y Bizancio vid. Pareti 1961, 86-87). Hamilton 
el mes de Jacintio, dentro del cual se celebraban las Jacintias, que son fiestas caniculares, ${ }^{8}$ lo que vendría a apoyar la hipótesis de que el año lacedemonio empezaba antes del equinoccio de otoño, quizá hacia la segunda parte del verano. A los efectos de cálculo, nosotros situaremos el inicio del año lacedemonio en verano, más bien hacia la última parte de dicha estación y, esta hipótesis nos servirá tanto para datar el año lacedemonio en que Agesilao llegó al trono como el resto de los que comprende su reinado.

En el cómputo dinástico egipcio habitual los años de los reinados de los faraones egipcios eran calculados en relación con el calendario civil egipcio, de manera que cada año de un monarca correspondía a un año egipcio. Además, los años de reinados de los diferentes faraones se referían a años completos de forma que los días o meses residuales del año en que tenía lugar la muerte de un rey eran asignados al primer año de su sucesor. Esto fue establecido hace tiempo por Skeat y Samuel ${ }^{9}$ y ha sido aceptado por otros autores como Lloyd. ${ }^{10}$ En consecuencia, el último año de un rey recaía en su último año completo y no en el de su fallecimiento, que era asignado a su sucesor, y el primer año de un rey correspondía, por tanto, al de su ascenso al trono, que se computaba, a efectos cronológicos, como

1982, 295 y Richer 1998, 301-304 situaron el comienzo del año lacedemonio hacia el equinoccio de otoño. Asimismo, PARETI $(1961,213$ y ss.) y Richer $(1998,155-198)$ defendieron para el calendario espartano un ciclo "octaetérico" mediante el cual se insertaría un mes intercalar en los años tercero, quinto y octavo en cada período de ocho años. Sobre esta base, Pareti reconstruyó el calendario entre los años 491/0 y 220/19. Dicha

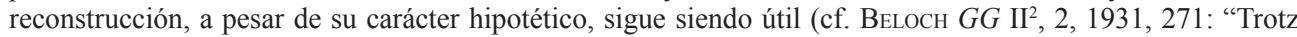
ihres hypothetischen Charakters ist die Tabelle nützlich und dankenswert, weil sie uns die Dinge konkret vor Augen führt"). Por último, debemos tener en cuenta además que el momento del comienzo del año lacedemonio permaneció inalterado al menos entre los siglos V y III (BELOCH $G G \mathrm{II}^{2}, 2,1931,270-271$ ).

8 A pesar de la importancia histórica de Esparta, nuestro conocimiento del calendario espartano es notablemente inexacto ya que no disponemos de una lista completa de meses ni tampoco conocemos con exactitud el orden de los mismos (cf. SAMUEL 1972, 92-94; TRÜMPY 1997, 135-136). Con todo, TRÜMPY (1997, 135-140, especialmente 139) ha podido recomponer con bastante verosimilitud el orden de los meses laconios, tomando como base no sólo la evidencia existente en la propia Lacedemonia sino también los calendarios de Bizancio, Epidauro y Taormina. En su reconstrucción, Jacintio es el primer mes del calendario lacedemonio. Para la celebración de las Jacintias en verano puede consultarse: PetTERsson 1992, 12-13 y nn. 24-25.

9 SKeat 1954, 2. Cf. especialmente SAmuel 1962, 4: "In this system, any regnal year 1 begins immediately upon the accession of the king, and year 2 begins on the following Thoth 1 [primer mes del año, cf. infra en esta misma nota], the first day of the Egyptian year. The Canon, which lists the number of years of every reign, counts only the number of Egyptian years completed. Any part of the last year of a ruler, that is, Thoth 1 to the date of his death, is suppressed, and the whole year is placed in the reign of his successor". El calendario civil egipcio se dividía en doce meses de 30 días, que se distribuían en grupos de cuatro según las tres estaciones (akhet o inundación, peret o siembra, shemu o recolección), a los que se sumaban cinco días al final de cada año (días epagomenos) para un total de 365 días. Los meses se dividían a su vez cada uno de ellos en tres períodos de diez días. Como no se añadía la cuarta parte de un día que tiene en exceso cada año solar astronómico, el calendario egipcio perdía un día cada cuatro años. En consecuencia, se convirtió en un "calendario errante", en el que los acontecimientos periódicos astronómicamente fijos vagaban por los meses del calendario, así, por ejemplo, el orto heliaco de la estrella Sirio, que marcaba el comienzo del año en el primer día del mes de Thot de la estación de akhet. Sobre el calendario egipcio puede verse Spalinger 2001, 224-227, que recoge también la bibliografía correspondiente.

10 Cf. Lloyd 1984 (reimpr. 2006), 356 para las dinastías egipcias XXVIII a XXX: "It is evident that these year-totals were calculated in terms of Egyptian civil years and generally reflect the last completed regnal year, i.e. any residual days or months in the year of a king's death were simply assigned to the first regnal year of his successor". 
un año completo. Finalmente y para el período que nos ocupa, la primera mitad del siglo IV, hay que tener en cuenta que el año egipcio comenzaba a mediados o finales de noviembre. ${ }^{11}$

La XXX dinastía egipcia, que se extiende aproximadamente desde 379 a la conquista persa, iniciada en 343/2, incluye tres faraones, Nectanebo I, Teos o Tacos y Nectanebo II. ${ }^{12}$ Como ya hemos apuntado, dicha dinastía es coetánea de la última parte del reinado de Agesilao y, a través de ella, intentaremos datar el año de la muerte de Agesilao. A partir de aquí nos remontaremos luego hasta la fecha del comienzo de su reinado. Los papiros escritos en versión demótica y publicados a partir de 1998 nos ayudarán en esta tarea. ${ }^{13}$

Desde un punto de vista expositivo, tras esta parte introductoria, trataremos en la siguiente sección de la extensión de los reinados de Agesilao II y de su antecesor, Agis II, de acuerdo con las noticias transmitidas por los autores griegos, para centrarnos, por último, en la dinastía XXX egipcia y en su validez para reconstruir la fecha del ascenso al trono de Agesilao II y la cronología de su reinado. Tomando estos datos como punto de partida, intentaremos fechar los acontecimientos acaecidos en Grecia continental y en Asia Menor entre los años 403 a 396.

Por último, dos acontecimientos, situados justo al principio y al final del período aquí considerado, 403 a 396, ofrecen una datación segura y nos sirven para enmarcar nuestro análisis. Tras el final de la Guerra del Peloponeso y el establecimiento de un violento régimen oligárquico en Atenas, ${ }^{14}$ la restauración democrática ateniense tuvo lugar indudablemente en el arcontado de Euclides, que se extiende entre el verano de 403 y el verano de 402 , y se conmemoraba todos los años el doce del mes de Boedromión ya que, justo en ese día, los demócratas habían entrado en Atenas procedentes del Pireo y habían efectuado una solemne procesión a la Acrópolis. ${ }^{15}$ Esto emplaza el restablecimiento de la democracia en Atenas en los primeros días de octubre de 403 y constituye el primer acontecimiento del período. Por otra parte, según Jenofonte, ${ }^{16}$ en el momento en que Agesilao entraba en Beocia procedente de Asia al mando de un ejército o, a decir de Plutarco, ${ }^{17}$ cuando estaba acampado ya en Queronea, se observó un eclipse y, en ese mismo día, Agesilao recibió la noticia de la derrota espartana en la batalla naval de Cnido. Dos o tres días más tarde, tuvo lugar la batalla de Coronea. ${ }^{18}$

11 Cf. Kienitz 1953, Traunecker 1979 o Salmon 1985, 182 que fechan el primer año de Nectanebo I, el primer faraón de la dinastía XXX, a partir de noviembre de 380. Lloyd 2006, 358: “At this period [404-332], the Egyptian civil calendar began in the middle of November".

12 Sobre la dinastía XXX se pueden consultar por ejemplo Bickermann 1934; SALMON 1985, 162-166; LLOYd 1984; PeRdu 2010.

13 RyHOLt 1998, 2002.

14 X. Hell. 2.2.10-4.43; Diod. 13.107.1-14.6.3, 32.1-33.6.

15 Arist. Ath. Pol. 39.1; Plu. Mor. 349 F; Cloché 1968, 247.

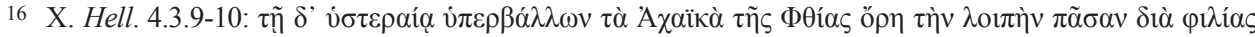

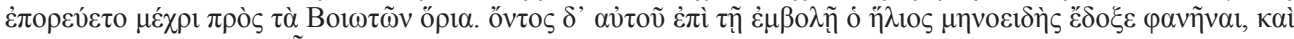

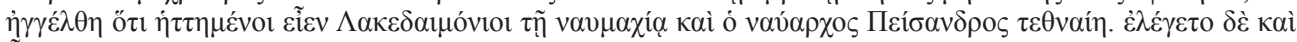

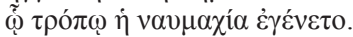

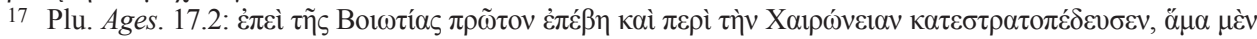

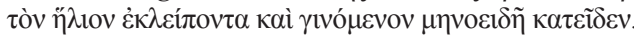

18 X. Hell. 4.3.15; Plu. Ages. 18.1. 
Dicho eclipse corresponde al 14 de agosto de 394 y, como sabemos que Agesilao regresó a Europa cuando comenzaba su tercer año de campaña en Asia Menor, es incontrovertible que su actividad militar en esta zona se inició en $396 .{ }^{19}$

\section{LA EXTENSIÓN DE LOS REINADOS DE AGIS II Y AGESILAO II}

Diodoro (12.35.4) sitúa el ascenso al trono de Agis II, el rey a quien habría de suceder Agesilao, ${ }^{20}$ en el año ático de 434/3 y afirma que reinó veintisiete años. ${ }^{21}$ Sin embargo, tras su subida al trono, Agis no vuelve a aparecer en el relato diodoreo hasta el arcontado de Arquias (419/8) ${ }^{22}$ y reaparece nuevamente en 405/4 cuando contaría, en la cronología de Diodoro, con al menos veintinueve años de reinado.$^{23}$ De este modo, de la propia evidencia interna del siciliota, se infiere que su testimonio es erróneo o bien en el año del ascenso al trono de Agis o bien en la duración de su reinado o bien en ambos.

De acuerdo con el testimonio de Tucídides, ${ }^{24}$ Arquidamo II, el padre de Agis II, comandó las primeras invasiones de los lacedemonios y sus aliados en el Ática que tuvieron lugar en los años 431 y 430. En 429, Arquidamo dirigió el asedio de Platea y a principios del verano de 428, hacia el mes de mayo, encabezó una nueva expedición contra el Ática. Esto es, se hallaba todavía vivo en el año espartano de 429/8. ${ }^{25}$ La invasión del año siguiente, en 427, estuvo liderada por Cleómenes, hermano del exiliado (y depuesto) rey Plistoanacte, de la casa agíada, puesto que el hijo de Plistoanacte, el rey Pausanias, era menor de edad. ${ }^{26}$ Finalmente, Agis mandó la expedición que tuvo lugar a comienzos de la estación para la campaña en el verano de $426 .{ }^{27} \mathrm{En}$ este momento, año espartano 427/6, Agis era ya rey y Arquidamo II habría fallecido, por consiguiente, entre mayo de 428 y mayo de $426,{ }^{28}$ esto es, entre su última expedición en el Ática y la primera de Agis.

19 BuCKLER 2003, 58 y ss.

20 Agis II era el primogénito del diarca de la casa euripóntida, Arquidamo II, e hijo de su primera esposa, Lampito (cf. Hdt. 6.71; Plu. Ages. 1.1 -que la llama Lampido-; Paus. 3.15.1). Sobre Arquidamo II: NIESE 1895; Poralla 1984, n 157, 32-33. Acerca de Agis II: Wissowa 1895; Poralla 1984, nº 26, 11-13. Agesilao era asimismo hijo de Arquidamo y de su segunda esposa, Eupolía, y era mucho más joven que su hermano mayor o hermanastro. Por consiguiente, como primero en la línea sucesoria, a la muerte de Arquidamo, el trono le correspondió a Agis (Plu. Ages. 1.1; X. Ages. 9.6). Acerca de Eupolía puede verse: Poralla 1984, nº 313, p. 57. Para Agesilao: Niese 1894; Poralla 1984, $\mathrm{n}^{\circ}$ 9, 6-8.

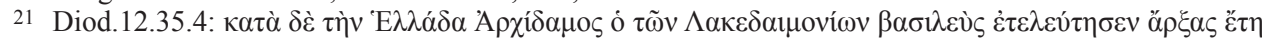

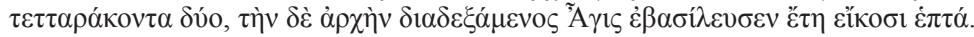

22 Diod. 12.78.2-4.

23 Diod. 14.17.4.

24 Th. 2.10-12, 18-23, 47. Vid. Diod. 12.42.6-8.

25 Th. 2.71-78; 3.1; Diod. 12.47,1-2.

26 Th. 3.26; Poralla 1984, $\mathrm{n}^{\circ}$ 438, 77. Plistoanacte fue depuesto en 446 (Th. 2.21; 3.26; Plu. Per. 22; Poralla 1984, n 613, 106) y repuesto hacia 426-424 (Th. 5.16). Murió en 408/7 (Diod. 13.75.1). Sobre el rey Pausanias, cf. Poralla 1984, no 596, 103-104. Acerca de las minorías de edad en la realeza espartana puede consultarse García IGLESIAS 1990, 43-44, nn. 27-30.

27 Th. 3.89. Comandó también la expedición correspondiente al año 425 (Th. 4.2.6).

28 Hamilton 1982, 282-283; ID. 1991, 18-19; Tuplin 1993, 203. 
Sobre la base del testimonio de Tucídides se puede afirmar que Agis comenzó a reinar bastante tiempo después de 434/3. Sin embargo, Diodoro puede ser veraz en uno de los datos que nos transmite: el relativo a la duración de veintisiete años para el reinado de Agis. Tal extensión del reinado de Agis es al menos compatible con el relato de Tucídides, de manera que se pudiera pensar que si bien Diodoro se equivocó al adscribir el comienzo del reinado de Agis al arcontado ático de 434/3, anotó, en cambio, correctamente sus años de reinado.

No es fácil esclarecer la razón por la cual Cleómenes y no Agis estuvo al frente de la expedición de 427, la que media entre la campaña de Arquidamo de 428 y la del propio Agis de 426. Quizá podamos suponer que Arquidamo, si bien se hallaba enfermo, permanecía todavía con vida a principios del verano de 427 , en el momento de empezar la estación para campaña. De este modo, Agis no habría accedido aún a la corona y sería precedido en jerarquía por Cleómenes, el tutor del joven diarca Pausanias. Esta última hipótesis apuntaría a una cronología "baja" para el comienzo del reinado de Agis II, entre el verano de 427 y el verano de 426.

En relación con el reinado de Agesilao, Plutarco (Ages. 40.2) dice que Agesilao reinó cuarenta y un años y que, de ellos, durante más de treinta, fue hegemón y rey de casi toda Grecia hasta la batalla de Leuctra. ${ }^{29}$

Si a la noticia de la extensión del reinado de Agesilao II, cuarenta y un años, unimos lo que hemos dicho para el reinado de Agis II, veintisiete años con el comienzo en 428, 427 o 426, Agesilao II habría comenzado a reinar entre los años 401 y 399 y su reinado habría alcanzado hasta los años 360 a 358. Las mejores posibilidades, en la cronología "baja", son 400 a 359 o 399 a 358.

Aunque Bommelaer consideró que era posible, quizás, que Plutarco vinculara el final del dominio espartano con la invasión de Laconia por parte de Epaminondas y la independencia de Mesenia, que tuvieron lugar entre finales de $370 \mathrm{y}$ comienzos de $369,{ }^{30}$ Plutarco apunta claramente que Agesilao dominó Grecia hasta Leuctra. Dicha batalla se libró a principios de julio o a principios de agosto de 371, en todo caso al comienzo del año ático de 371/0, en el año espartano 372/1. Esto parece patente por el hecho de que también Plutarco (Cam. 19.2) sincroniza los calendarios beocio y ático afirmando que los beocios, el día cinco del mes Hipodromión, que se corresponde con el ático de Hecatombeón, obtuvieron dos grandes victorias, una, la de Leuctra, y otra, la de Geresto, más de doscientos años antes, en la que vencieron a Latamias y a los tesalios. Hipodromión ${ }^{31}$ es el octavo mes del calendario beocio, cuyo año empezaba en los primeros días de enero, pasado el solsticio de invierno, y Hecatombeón es el primer mes del año ático, que corresponde a julio-agosto. Si corría entonces el trigésimo año del reinado de Agesilao, el diarca habría comenzado a reinar en 401 (año espartano 401/400). Si había completado su trigésimo año y transcurría, por tanto, su trigésimo primero, habría comenzado a reinar en 402 (año 402/1). Esta última

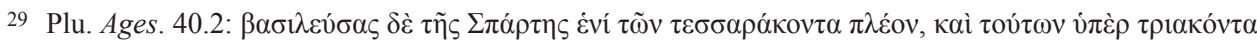

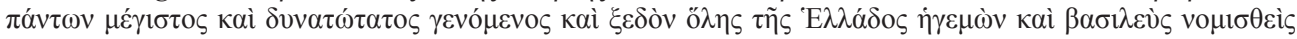

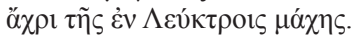

30 Bommelaer 1981, 174-175.

31 Roesch 1982, 37. 
fecha es sumamente improbable porque lleva el comienzo del reinado de Agis III al año 429, todavía en vida de Arquidamo II.

En definitiva, las noticias que nos han transmitido los autores griegos sobre el ascenso al trono de Agesilao II no son concluyentes. Si los años reinados de los reyes espartanos se contabilizaban desde el comienzo al trono, quedan abiertas tres posibilidades (A, B, C, vid. tabla 1): los años 401, 400 y 399. Si se contabilizaban por años espartanos tendríamos también tres posibilidades 402/1, 401/0, 400/399. ${ }^{32}$

\begin{tabular}{|c|c|l|l|l|l|l|}
\hline Diarca & A & & B & & C & \\
\hline Agis II & $428^{*}$ & $429 / 428 * *$ & 427 & $428 / 427$ & 426 & $427 / 426$ \\
\hline Agesilao II & 401 & $402 / 401$ & 400 & $401 / 400$ & 399 & $400 / 399$ \\
\hline
\end{tabular}

Tabla 1. Las fechas para el ascenso al trono de los reyes Agis II y Agesilao II

* Desde el ascenso al trono.

** Años lacedemonios.

Se comprende entonces las dificultades que ha tenido la historiografía para datar el año de ascenso al trono de Agesilao. Así, Niese propuso el año $401 ; ;^{33}$ Beloch, Funke, Cartledge y Alonso Troncoso, ${ }^{34}$ el 400; Richer hacia $400-398 ;{ }^{35}$ Cary, el 399; ${ }^{36}$ García Iglesias, entre 400 y $399^{37}$, y Hamilton y Fornis, el año $398 .{ }^{38}$

\section{LA XXX DINASTÍA EGIPCIA}

Jenofonte asegura que Agesilao accedió al trono siendo aún joven ${ }^{39}$ y que, cuando contaba con unos ochenta años, fue a Egipto a ayudar al faraón contra los persas. ${ }^{40}$ El faraón que le había llamado -Jenofonte no indica el nombre de ninguno de los reyes egipcios- huyó a Sidón de Fenicia y los egipcios nombraron a dos faraones, de manera que Agesilao eligió a uno de ellos y, derrotando al otro en batalla, aseguró en el poder al primero. ${ }^{41}$ Una vez que hizo del nuevo faraón un aliado de los lacede-

32 Más difícil es considerar que Agis II muriera en la segunda parte del año 399 y que Agesilao comenzara a reinar en el año espartano 399/8 puesto que sabemos que Agis era rey ya en el año 427/6 y el año 399/8 nos llevaría a una extensión de veintiocho años para el reinado de Agis.

33 Niese 1894, 796.

34 Beloch 1927, 3.1.17-18; Funke 1980, 36, n. 31; Cartledge 1987, 99 y Alonso Troncoso 1987, 495.

35 RICHER 1998, 547.

36 CARY 1969 [1927], 32-33.

37 García Iglesias 1990, 50.

38 HamiLTON 1982; ID. 1991, 1; ForNIS 2003, 166.

39 X. Ages. 1.6.

40 X. Ages. 2.28.

41 X. Ages. 2.30-31. 
monios y recibió mucho dinero del mismo, Agesilao, en pleno invierno, zarpó para Esparta, con la finalidad de que la ciudad no quedara inactiva al año siguiente frente a los enemigos. ${ }^{42}$

Plutarco, por su parte, afirma que Agesilao tenía más de ochenta años cuando navegó hacia Egipto y que contaba ochenta y cuatro cuando murió. ${ }^{43}$ De acuerdo con este autor, Agesilao fue llamado por el faraón Tacos, pero, una vez en Egipto, se pasó a Nectanebo II y junto con él luchó contra un usurpador, cuyo nombre no se indica y que tenía por centro la ciudad de Mendes (Plu. Ages. 36.1-40.2). Tras ello, Nectanebo II trató de convencer a Agesilao para que pasara el invierno en Egipto, pero él deseaba regresar a su patria porque ésta se hallaba en guerra, necesitaba dinero y se veía obligada a mantener mercenarios. ${ }^{44}$ Por consiguiente, se dio a la mar pero, como había llegado ya el invierno, no pudo cruzar hacia el Peloponeso y tuvo que atracar en la costa africana, en un lugar desierto denominado el "puerto de Menelao", donde murió. ${ }^{45}$

Los relatos de Plutarco y de Jenofonte nos abren la posibilidad de relacionar el reinado de Agesilao y su ascenso al trono con la cronología de la dinastía XXX egipcia. ${ }^{46}$ Como veremos más adelante, Nectanebo I, el primer faraón de la XXX dinastía, comenzó a reinar hacia 379/8. En los postreros años de su reinado, asoció al trono a su hijo Teos o Tacos. ${ }^{47}$ Una vez que murió Nectanebo I, según Diodoro, en el arcontado de Molón (361/0), ${ }^{48}$ Teos/Tacos comenzó a preparar la conquista de Siria y Palestina, retomando lo que había sido la anterior política expansionista de Acoris (c. 392/1-381/0), uno de los faraones de la XXIX dinastía. Con este objetivo, selló una alianza con Esparta, reclutó una gran fuerza de mercenarios, cuyo mando ofreció a Agesilao, y reunió una flota de doscientos trirremes comandada por el ateniense Cabrias. Agesilao aceptó, viajó a Egipto al frente de mil hoplitas, a bordo de la flota de Cabrias, y asumió el mando de los mercenarios. Concluidos los preparativos, el ejército, a las órdenes del propio faraón, se puso en marcha. Agesilao lideraba a los mercenarios mientras que la flota de Cabrias flanqueaba el avance egipcio. ${ }^{49}$ Para el tiempo que se prolongara la expedición, Tacos dejó, como regente del país, a su hermano Tjahapimu, ${ }^{50}$ cuyo hijo, el futuro Nectanebo II, acompañaba al rey. Sin embargo, una vez que Tacos abandonó Egipto, en una maniobra con seguridad planeada de antemano, el regente hizo proclamar a su hijo como faraón. Todo el ejército se pasó entonces a Nectanebo II y Tacos tuvo que escapar y refugiarse en Sidón. De ahí huyó a la corte del rey persa Artajerjes II. La revuelta contó también con la colaboración

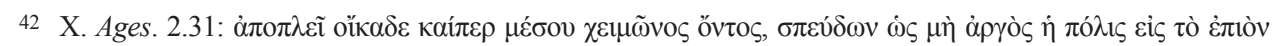

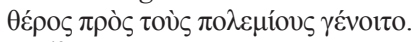

43 Plu. Ages. 36.2, 40.2.

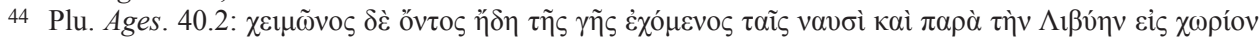

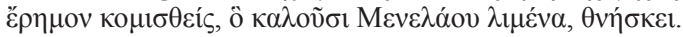

45 Plu. Ages. 40.3.

46 Cf. Hamilton 1982, 293-294.

47 EngSheden 2006, 63.

48 Diod. 15.90.1.

49 Diod. 15.90.2, 92.2-3.

50 De Meulenaere 1963, 91; von Kaenel 1980, 40. 
de Agesilao, que sostenía malas relaciones con Tacos. ${ }^{51}$ Sin embargo, el golpe no se impuso sin dificultades. De hecho, Nectanebo II hubo de abandonar la expedición en Siria y Palestina y regresar a Egipto para sofocar una rebelión, favorable al faraón depuesto, que había estallado en torno a Mendes, la ciudad que había sido cabeza de la dinastía XXIX. Con la ayuda de Agesilao, Nectanebo II consiguió acabar con toda resistencia. Éste es en resumen, el relato de los acontecimientos que ocupan la estancia de Agesilao en Egipto, paliando, en la medida de lo posible, los múltiples errores que encierra la narración de Diodoro. Y es así que el siciliota confunde al ignoto pretendiente al trono procedente de Mendes con Nectanebo y afirma la victoria final de Tacos frente Nectanebo II, sustituyendo así a Nectanebo por Tacos. ${ }^{52}$ Por último, resulta evidente que todo el curso de la acción, entre los preparativos y la campaña, difícilmente pudo ocupar un único año ni tampoco, como más adelante apuntaremos, la aventura egipcia de Agesilao habría tenido lugar en el arcontado de Molón sino en años posteriores.

Como dijimos, los reinados de los faraones egipcios se basaban en el año civil egipcio que comenzaba en noviembre y la duración de los reinados de los diferentes faraones se expresaban en años completos de manera que los últimos días o meses del reinado de cada uno de ellos se incluían en el primer año de su sucesor.

Para establecer la cronología de los faraones de la XXX dinastía contamos con los

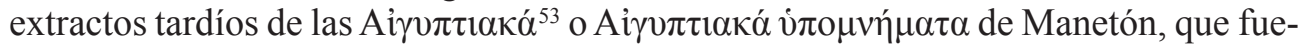
ron escritas en el tiempo de Tolomeo II Filadelfo $(282-241)^{54}$ y que no han sobrevivido. En realidad disponemos de tres sucintas listas basadas en el relato de Manetón que recogen escuetamente el nombre de los faraones y sus respectivos años de reinado. ${ }^{55}$ Dos fueron compiladas por Jorge el Monje ${ }^{56}$ (c. 800 d.C.), más conocido como Jorge Sincelo, debido al cargo eclesiástico que desempeñaba como secretario ( $\sigma 0 ́ \gamma \kappa \varepsilon \lambda \lambda \circ \varsigma)$ del patriarca de Constantinopla, Tarasio. Jorge Sincelo no utilizó directamente la obra de Manetón sino que compendió a su vez los epítomes confeccionados por otros cronógrafos cristianos anteriores a él, como Sexto Julio Africano ${ }^{57}$ y Eusebio de Cesarea, de ahí que poseamos una lista de Jorge Sincelo basada en Julio Africano y otra del

51 X. Ages. 2.28-31; Diod. 15.93.3-5 (erróneamente dice que Tacos huyó a Arabia); Nep. Ages. 8; Plu. Ages. 36.1-39.5; Polyaen. 3.11.7; Lloyd 1984, 341, 348-349. Sobre la historia de la dinastía XXX puede verse Salmon 1985, 162-166; Lloyd 1984, 342-344; Perdu 2010, 154-157.

52 Diod. 15.93.2-6.

53 Para Manetón emplearemos la edición de WADDELl 1941 y la traducción de JiMÉnez FernÁNDEZ - JiMÉ-

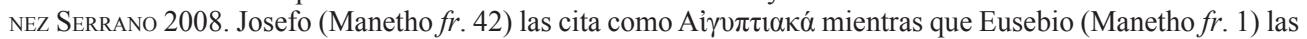

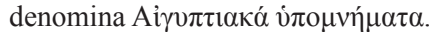

54 Cf. JimÉnez FernÁNDEZ - JimÉnez SERrano 2008, 20-22.

55 Manetho frgs.74 a, b y c (para la dinastía XXX) y frgs. 75 a, b y c para la dinastía XXXI (persa). A ellos hay que sumar el $\mathrm{frg}$. $\varepsilon$ de la edición de Jiménez FERnÁndeZ - JimÉnEz SERrano 2008, 151, procedente de S. Jerónimo.

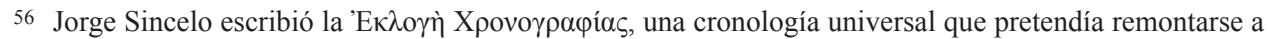
Adán y que alcanzaba hasta Diocleciano, con la pretensión de demostrar que Jesucristo nació en el año 5500 después de la Creación del mundo. Cf. las ediciones de Mosshammer 1984 y la más reciente de Alder - TufFIN 2002.

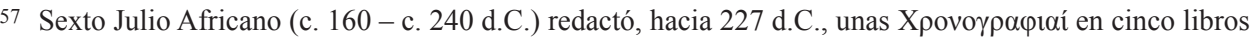
que iban desde la Creación del mundo, que fijaba en 5500, al reinado de Heliogábalo (221 d.C.). Aunque su obra no se conserva, salvo por los fragmentos recogidos en escritos posteriores, Julio Africano sentó las bases 
mismo autor, Sincelo, pero fundamentada en Eusebio. Una tercera lista fue reunida por la llamada Versión armenia de la Crónica de Eusebio de Cesarea. ${ }^{58} \mathrm{~A}$ esta información, bien parca, hay que sumarle la denominada Crónica demótica, un papiro de principios del siglo II a.C., no siempre fácil de interpretar, que presenta una serie de oráculos y su exégesis correspondiente dentro de un tono decididamente antipersa. ${ }^{59}$ Esta sería (tabla 2), en consecuencia, la extensión de los reinados de los faraones de la dinastía XXX de acuerdo con las diferentes versiones conservadas:

\begin{tabular}{|c|c|c|c|}
\hline $\begin{array}{c}\text { Frg. } 74 \mathrm{a}^{*} \\
\text { De Sincelo, según } \\
\text { Africano }\end{array}$ & $\begin{array}{c}\text { Frg. } 74 \text { b } \\
\text { De Sincelo, según } \\
\text { Eusebio }\end{array}$ & $\begin{array}{c}\text { Frg. } 74 \mathrm{c} \\
\text { Crónica I. Versión } \\
\text { armenia de Eusebio }\end{array}$ & Crónica demótica ${ }^{* *}$ \\
\hline Nectanebo I - 18 años & Nectanebo I - 10 años & Nectanebo I - 10 años & 4.13-15. Nectanebo I - \\
\hline Teos/Tacos - 2 años & Teos/Tacos - 2 años & Teos/Tacos - 2 años & $\begin{array}{l}\text { 4.16. Teos/Tacos - } \\
1 \text { año }\end{array}$ \\
\hline Nectanebo II - 18 años & Nectanebo II - 8 años & Nectanebo II - 8 años & $\begin{array}{l}\text { 4. 18-19. Nectanebo II - } \\
18 \text { años }\end{array}$ \\
\hline Total: 38 años & Total: 20 años & Total: 20 años & Total: 38 años \\
\hline
\end{tabular}

Tabla 2. Extensión de los reinados de los faraones de la dinastía XXX.

${ }^{*}$ Cf. Waddell 1941, 182-184: Manetho, fr. 74 a (Sincelo a través de Julio Africano): $\alpha^{\prime}$

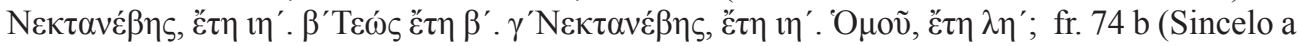

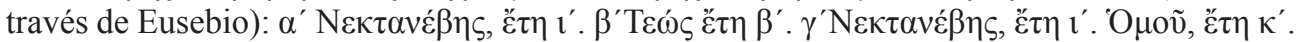
Manetho, fr. 74 c (versión armenia de Eusebio, Cronica I): Nectanebis, annis X. Teos, annis II. Nectanebus, annis VIII. Summa annorum XX). Vid. además Jiménez Fernández - Jiménez Serrano 2008, 151.

${ }^{* *}$ Spiegelberg 1914, 18.

De acuerdo con Sincelo, Julio Africano asignaba dieciocho años a Nectanebo I y dos a su hijo y sucesor, Teos, mientras que Eusebio, ya sea a través de Sincelo o en

de la cronografía cristiana y suele ser considerado además como una fuente de información bastante fiable. Vid. la edición de WaLLRAFF 2007.

58 Eusebio de Cesarea compuso el Xpovikóv, una Historia universal en dos libros que iba desde Abraham al 325 d.C. El primer libro contenía un resumen histórico dispuesto por regiones y el segundo una tabla cronológica que sincronizaba de forma analística los acontecimientos en diferentes ámbitos. Ambos libros se conservan básicamente a través de una versión armenia, mientras que el Libro II fue traducido al latín por San Jerónimo. Cf. la edición de Mosshammer 1979.

59 Abreviada como $P$. Chronik. Se han perdido el principio y el final de la misma de manera que se conservan cinco columnas completas (II-V), el final de la primera y el comienzo de la VI. Aunque su autor pretende escribir en época de Nectanebo II, la obra fue compuesta en la primera parte de la época tolemaica, cf. JoHNSON 1974, 1-5; BresCiani 1985, 506, 525-526. Felber (2002) ha interpretado la Crónica demótica como una obra propagandística en favor de Tolomeo I. Nosotros emplearemos la edición de SPIEGelberg 1914. 
la Versión armenia, atribuía únicamente diez años de reinado a Nectanebo I y dos a Teos. La Crónica demótica (P. Chronik. 4.13-15) apunta la mayor verosimilitud del testimonio de Julio Africano ya que adjudica a Nectanebo I diecinueve años de reinado y uno solo a Teos, esto es, como en el caso de Julio Africano, veinte años para la suma de ambos reinados. ${ }^{60}$ Asimismo, la Crónica demótica (4.16) nos informa de que Nectanebo I asoció al trono a Tacos desde el año decimosexto de reinado. A partir de aquí no resulta difícil conciliar los testimonios de Julio Africano y de la Crónica demótica. Podemos considerar, simplemente, que Nectanebo I reinó dieciocho años completos, de los cuales en sus dos últimos asoció en el trono a su hijo, y que murió en el curso de su decimonoveno año. Este último año sería contado como el primero de su sucesor en el caso de Julio Africano pero adscrito sin embargo (y erróneamente) a Nectanebo I por la Crónica demótica. Aparentemente, la tradición eusebiana conocía la existencia de dos faraones con el nombre de Nectanebo, pero la extensión de uno solo de sus reinados, dieciocho años $\left(\eta \eta^{\prime}\right)$ que procedería a dividir equivocadamente entre Nectanebo I ( $\left.\imath^{\prime}\right)$ y Nectanebo II $\left(\eta{ }^{\prime}\right)$.

Por lo que se refiere a Teos/Tacos, el segundo faraón de la XXX dinastía, salvo en el caso de Crónica demótica (4.16), hay acuerdo en el resto de las fuentes, ya sea en Julio Africano, Eusebio o en la Versión armenia, en asignarle dos años. No resulta en exceso complicado armonizar todas las noticias que poseemos sobre la extensión del reinado de Teos/Tacos. En consecuencia, el primer año de reinado de Teos se correspondería con el del fallecimiento de Nectanebo I, el decimonoveno de este último rey según la Crónica demótica pero que no llegó a completar. Tras este primer año, Teos habría reinado un año completo, el segundo del resto de las fuentes y el único que refiere la Crónica demótica, y habría sido depuesto en el curso de su tercer año, que habría sido asignado por todos los autores a su sucesor, Nectanebo II, como el primero de su gobierno.

En lo que respecta al último faraón de la XXX dinastía, Nectanebo II, Julio Africano le adjudica dieciocho años de reinado mientras que Eusebio, ya sea en Sincelo o en la Versión armenia, le otorga únicamente ocho. La cifra de Julio Africano se ve corroborada por la Crónica demótica (4.18-19) que le atribuye también dieciocho años y por una dedicatoria procedente del templo Edfú que se data en el año decimoctavo de su reinado ${ }^{61}$ Nectanebo II habría reinado, pues, al menos durante dieciocho años, siendo el primero de su gobierno el tercero de Teos y habría sido depuesto por las tropas persas en su decimonoveno año. Tendríamos así dieciocho años para Nectanebo I, dos para Teos y dieciocho para Nectanebo II, con un total de treinta y ocho años egipcios completos para toda la dinastía XXX.

Un cuento de época tolemaica, conocido bajo los nombres del Sueño de Nectanebo o la Profecía del escultor Petesis, menciona una luna llena que tuvo lugar el día 21 del mes de Pharmuti, exactamente la noche que va del 21 al 22, en el año decimosexto del reinado de Nectanebo. ${ }^{62}$ En 343 hubo una luna llena la noche del 5 al 6 de

60 JoHNSON 1974, 14-16.

61 Chassinat 1932, 239; Kienitz 1953, Appendix 10, Nectanebo (II), no 9; MecKs 1972, 133.

62 Col. II. 1-5 (ed. Koenen). Este relato fue escrito en griego en un papiro de principios del siglo II (P. Leiden I 396). Procedente del Serapeum de Alejandría, formaba parte del archivo de Apolonio quien sólo de- 
julio, precisamente del 21 al 22 de Pharmuti, por lo que dicho año correspondería al decimosexto del reinado de Nectanebo II, esto es, al año egipcio que daba principio en noviembre de 344 y que alcanzaba hasta noviembre de $343 .{ }^{63}$ El decimoctavo año de Nectanebo II se extendería entonces entre noviembre de 342 y noviembre de 341 , por lo que este faraón habría sido depuesto a partir de su decimonoveno año (341/0), ya con la invasión persa comenzada. Es decir, aunque la última campaña persa para adueñarse de Egipto comenzó hacia el otoño de 343, dentro del año egipcio de $344 / 3,{ }^{64}$ precisamente en el decimosexto año de Nectanebo II y, quizá esa es la razón a mi juicio de la fecha a la que nos retrotrae el Sueño de Nectanebo, la conquista pudo dilatarse algún tiempo debido a la fuerte resistencia que opuso Nectanebo II, que pudo sostenerse o recuperar posiciones en el Alto Egipto. En esta dirección apuntarían la tradición manetoniana, la dedicatoria de Edfú antes comentada y, como veremos, la versión demótica del Sueño de Nectanebo que mencionan el decimoctavo año de reinado de Nectanebo II. Por consiguiente, Nectanebo habría resistido al menos desde el otoño de 343 y a lo largo de los años 343/2 y 342/1 y sólo habría sido depuesto definitivamente a partir de noviembre de 341, año egipcio $341 / 0$, en el que Artajerjes III Oco habría sido reconocido oficialmente como faraón. Nectanebo II tuvo que refugiarse en Nubia y nunca más regresó. ${ }^{65}$

La versión griega de la Profecía de Petesis fue copiada de un original egipcio. Esto se vio corroborado cuando, en 1998, comenzaron a publicarse cuatro manuscritos escritos en demótico, datados entre finales del siglo I y principios del II d.C., uno de los cuales (P. Carlsberg 562) contenía la versión demótica de la Profecía y los otros tres (P. Carlsberg 424, 499 y 559) recogían el comienzo de la continuación del relato. ${ }^{66}$ La versión demótica (lín. 1, edición Ryholt 1998) asegura que se trata de Nectanebo II y no de Nectanebo I y si bien indica una fecha en el año dieciocho de Nectanebo II debe tratarse de una confusión tardía, un lapsus calami, entre la fecha que figuraba en la Profecía y el último año del reinado de este faraón. De hecho, la luna llena del 21 al 22 de Pharmuti corresponde al año dieciséis de Nectanebo y no al dieciocho y los otros tres papiros demóticos mencionan expresamente el año dieciséis. ${ }^{67}$

bió copiar el principio del mismo y fue adquirido por J. d'Anastasy en 1820 (cf. RYноцт 1998, 197). Ha sido publicado en numerosas ocasiones. Editio princeps: LeEmans 1838, 122-129. Además, WiLcKEN 1905, 579596; Maspero 1911, 306-310; LaVagnini 1922, 37-42; Wilcken 1927; Manteuffel 1930, 10, y especialmente KoENEN 1985, 171-194, que es la edición que nosotros hemos seguido.

63 Maspero 1911, 309; LaVagnini 1922, 38; Wilcken 1927, 370; Bickermann 1934, 78-79; Koenen 1985, 184; Spalinger 1992.

64 Cf. Bickermann 1934, 80 y ss.; Kienitz 1953, 170-173; Johnson 1974, 10; Perdu 2010, 156.

65 Diod. 16.40-52. Los seis años de reinado en Egipto que Eusebio atribuye a Artajerjes III Oco, ya sea a través de Sincelo $(f r .75 \mathrm{~b})$ o mediante la Versión armenia ( $f r .75 \mathrm{c})$ pueden explicarse fácilmente suponiendo que Eusebio comenzó a contar desde el inicio de la invasión en 344/3. La noticia de Julio Africano ( $f r .75$ a) que, a través también de Sincelo, atribuye a Oco únicamente dos puede ser una confusión acerca del año en que finalizó la conquista (341/0), esto es, en el curso del décimo noveno de Nectanebo que fue asimismo el primero de Oco, pero que Julio Africano no contabilizó.

66 Ryногт 1998; ID. 2002. Parecen representar ejercicios de escribas. De hecho, los tres manuscritos P. Carlsberg 424, 499 y 524 son copias idénticas realizadas por el mismo escriba (RYноцт 1998, 197-198).

67 Ryнolt 1998, 200; ID. 2002, 228. 
Si el decimosexto año de Nectanebo II corresponde al año egipcio 344/3, su primer año completo contaría desde noviembre de 359 a noviembre de $358 .{ }^{68}$ Esto es, como sabemos que fue proclamado en plena expedición militar, su usurpación dataría del verano de 358, esto es, dentro del año egipcio 359/8. Teos/Tacos habría empezado a reinar en solitario en $361 / 0^{69}$ y su segundo y último año completo correspondería a 360/59. Esto nos lleva a fijar el primer año de Nectanebo en 379/8, que sería también el año de su usurpación y del final de la XXIX dinastía. ${ }^{70}$ De este modo, la cronología de la XXX dinastía egipcia quedaría establecida como sigue (tabla 3):

\begin{tabular}{|c|c|c|}
\hline Faraón & Años egipcios & N$^{\circ}$ de años \\
\hline Nectanebo I & $379 / 8-362 / 1$ & 18 \\
\hline Teos/Tacos & $361 / 0-360 / 59$ & 2 \\
\hline Nectanebo II & $359 / 8-342 / 1$ & 18 \\
\hline
\end{tabular}

Tabla 3. La dinastía XXX egipcia.

\section{CONCLUSIONES. EL ASCENSO AL TRONO DE AGESILAO II DE ESPARTA Y LA CRONOLOGÍA DE LOS AÑOS 403 A 396 A.C.}

Teniendo en consideración cuanto hemos venido diciendo acerca de la cronología de la XXX dinastía egipcia, podemos ahora acercarnos al momento del ascenso al trono de Agesilao II de Esparta. Como Nectanebo II accedió al trono en el verano de 358 y contó con el apoyo de Agesilao, el diarca estaba todavía vivo en dicho año. Tanto Jenofonte (Ages. 2.31) como Plutarco (Ages. 40.2) afirman que Agesilao zarpó hacia Esparta en pleno invierno o en medio del invierno. ${ }^{71}$ Parece claro que ambos deben referirse a que estaba para concluir la estación para la navegación que en la Antigüedad se abría hacia el 5 de marzo de cada año y, si bien se solía navegar entre mayo y septiembre, ${ }^{72}$ se cerraba a finales de septiembre de cada año. ${ }^{73}$ De hecho, los meses de julio y agosto eran los mejores para surcar los $\operatorname{mares}^{74} \mathrm{y}$ resultaba peligroso

68 Su primer año era 359/8 y habría accedido al trono antes del 21 de noviembre de 358 (cf. KoENEN 1985. 184).

69 BickeRMANN 1934, 78-79.

70 Los cuatro meses de reinado de Neferites II, el último faraón de la XXIX dinastía, caerían también en el año 379, sin bien su localización precisa no puede ser establecida. Es probable que, a efectos de cronología dinástica, su reinado fuera contabilizado como un año, 380/79, que sería también en el que muriera Acoris, el penúltimo faraón de la dinastía XXIX. El último año completo de Acoris habría sido, por lo tanto, 380/1. Teopompo (FGrH 115 F 103) dice que Nectanebo llegó a ser rey de Egipto antes del final de la rebelión de Evágoras que habitualmente se data en 380 pero que pudo caer también en el 379. Quizá Teopompo no se está refiriendo a la entronización formal de Nectanebo sino a su poder de facto ya que tenemos razones para considerar que Nectanebo se rebeló contra el faraón antes de alcanzar el trono (Cf. JoHnSON 1974, 8).

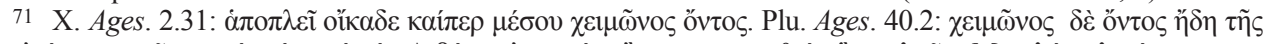

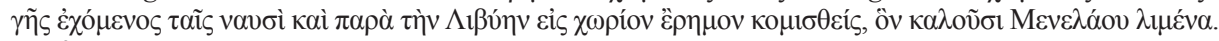

72 Veg. Re Mu. 4.49.

73 Apul. Met. 11.5, 16-17.

74 Hes. Op. 663-670. 
navegar después de septiembre. ${ }^{75}$ Todos estos testimonios apuntarían a que Agesilao se hizo a la mar quizá hacia la segunda parte del mes de septiembre de 358, ya dentro del año espartano de $358 / 7$, fecha en torno a la cual debió producirse precisamente su fallecimiento. Es posible que hubiera llegado a Egipto en la segunda mitad del año 359 y que la campaña en Siria y Fenicia y su regreso a Egipto para hacer frente junto a Nectanebo II a la sublevación mendita acaecieran en el año 358.

Como estaba vivo en 358 y murió este mismo año a lo largo del cuadragésimo primero de su reinado, el ascenso al trono de Esparta del rey Agesilao II debe fecharse en 399. Si tenía ochenta y cuatro años en el momento de su fallecimiento habría nacido en el año 442 o en 443, en el caso este último de que cumpliera años en la última parte del año. Habría accedido al trono cuando contaba con cuarenta y tres o cuarenta y cuatro años de edad. La batalla de Leuctra correspondería a su vigésimo octavo año de reinado y no al trigésimo, por lo que Plutarco (Ages. 40.2) redondeó erróneamente esta cifra.

Si contamos por años espartanos, como no llegó a completar el año 358/7, su último completo habría sido 359/8, de manera que Agesilao habría accedido al trono en el año 400/399. De este modo, Agis II, su predecesor, habría llegado al trono dentro del año espartano de 427/6, por lo que Arquidamo II estaría todavía vivo en el año espartano 428/7 (moriría entre finales de 427 y principios de 426). Esto explicaría que Cleómenes y no Agis, que todavía no era rey, mandara la expedición contra el Ática que tuvo lugar en 427.

La entronización de Agesilao y su reinado quedarían como sigue (tabla 4):

\begin{tabular}{|c|c|c|c|c|c|}
\hline $\begin{array}{c}\text { Años de } \\
\text { reinado }\end{array}$ & $\begin{array}{c}\text { Desde el comien- } \\
\text { zo de su reinado }\end{array}$ & Años espartanos & $\begin{array}{c}\text { Años de } \\
\text { reinado }\end{array}$ & $\begin{array}{c}\text { Desde el } \\
\text { comienzo de } \\
\text { su reinado }\end{array}$ & Años espartanos \\
\hline $\mathbf{1}$ & 399 & $400 / 399$ & $\mathbf{2 2}$ & 377 & $378 / 377$ \\
\hline $\mathbf{2}$ & 398 & $399 / 398$ & $\mathbf{2 3}$ & 376 & $377 / 376$ \\
\hline $\mathbf{3}$ & 397 & $398 / 397$ & $\mathbf{2 4}$ & 375 & $376 / 375$ \\
\hline $\mathbf{4}$ & 396 & $397 / 396$ & $\mathbf{2 5}$ & 374 & $375 / 374$ \\
\hline $\mathbf{5}$ & 395 & $396 / 395$ & $\mathbf{2 6}$ & 373 & $374 / 373$ \\
\hline $\mathbf{6}$ & 394 & $395 / 394$ & $\mathbf{2 7}$ & 372 & $373 / 372$ \\
\hline $\mathbf{7}$ & 393 & $394 / 393$ & $\mathbf{2 8}$ & 371 & $372 / 371$ \\
\hline $\mathbf{8}$ & 392 & $393 / 392$ & $\mathbf{2 9}$ & 370 & $371 / 370$ \\
\hline $\mathbf{9}$ & 391 & $392 / 391$ & $\mathbf{3 0}$ & 369 & $370 / 369$ \\
\hline $\mathbf{1 0}$ & 390 & $391 / 390$ & $\mathbf{3 1}$ & 368 & $369 / 368$ \\
\hline $\mathbf{1 1}$ & 389 & $390 / 389$ & $\mathbf{3 2}$ & 367 & $368 / 367$ \\
\hline $\mathbf{1 2}$ & 388 & $389 / 388$ & $\mathbf{3 3}$ & 366 & $367 / 366$ \\
\hline $\mathbf{1 3}$ & 387 & $388 / 387$ & $\mathbf{3 4}$ & 365 & $366 / 365$ \\
\hline $\mathbf{1 4}$ & 386 & $387 / 386$ & $\mathbf{3 5}$ & 364 & $365 / 364$ \\
\hline $\mathbf{1 5}$ & 385 & $386 / 385$ & $\mathbf{3 6}$ & 363 & $364 / 363$ \\
\hline $\mathbf{1 6}$ & 384 & $385 / 384$ & $\mathbf{3 7}$ & 362 & $363 / 362$ \\
\hline
\end{tabular}

75 Vid. San Pablo en Act. 27.9-10. 


\begin{tabular}{|l|l|l|l|l|l|}
\hline $\mathbf{1 7}$ & 383 & $384 / 383$ & $\mathbf{3 8}$ & 361 & $362 / 361$ \\
\hline $\mathbf{1 8}$ & 381 & $383 / 382$ & $\mathbf{3 9}$ & 360 & $361 / 360$ \\
\hline $\mathbf{1 9}$ & 380 & $381 / 380$ & $\mathbf{4 0}$ & 359 & $360 / 359$ \\
\hline $\mathbf{2 0}$ & 379 & $380 / 379$ & $\mathbf{4 1}$ & 358 & $359 / 358$ \\
\hline $\mathbf{2 1}$ & 378 & $379 / 378$ & & & \\
\hline
\end{tabular}

Tabla 4. El ascenso al trono y el reinado de Agesilao II de Esparta.

La fecha del año 399 para el ascenso al trono de Agesilao II de Esparta nos permite datar de una manera más acabada los acontecimientos capitales de la historia de Grecia y del Mediterráneo oriental entre los años 403 a 396. Así, en 399, probablemente todavía en el año espartano de 400/399, Agesilao II accedió al trono. Antes de la llegada al trono de Agesilao, si, como quiere Jenofonte (Hell. 3.2.21-31), la Guerra de la Élide se prolongó tres años, éstos serían 401, 400 y 399, lo que supone que Diodoro $(14.17 .4-12,34.1)$ que sólo anota dos, debe de estar equivocado. ${ }^{76}$ El estallido de la guerra habría tenido lugar entonces en el año 402/1, las expediciones militares espartanas ocuparían el verano de 401 y el verano de 400 y la capitulación caería antes de principios de la estación para la campaña de $399 .{ }^{77}$ Tras la firma de la paz con la Élide, Agis, en la primavera de 399, comandaría una expedición contra los mesenios que estaban establecidos en Naupacto y en una plaza fuerte que ocupaban en la isla de Cefalonia y que Diodoro (14.34.2-3) sitúa inmediatamente después del final del conflicto con los eleos. ${ }^{78}$ Desde Naupacto, se dirigiría a Delfos. A su regreso de Delfos y del Golfo de Corinto, cayó enfermo en Herea de Arcadia y murió poco después en Esparta (X. Hell. 3.3.1). Posiblemente en 401, mientras se producía la expedición de Ciro, los atenienses se anexionaron Eleusis que había surgido como comunidad separada, en la que se refugiaron los oligarcas atenienses, tras los acuerdos de reconciliación de octubre de 403 (X. Hell. 2.4.43). En este mismo año tendría lugar la ocupación tebana de Oropo, en la frontera con el Ática, ya que Diodoro (14.17.1-4) indica que la guerra contra la Élide comenzó en el arcontado de Mición (402/1) y fue coetánea de la ocupación tebana de Oropo. Finalmente, en octubre de 403, como dijimos, habría tenido lugar la restauración democrática en Atenas.

Una vez que Agesilao llegó al trono, si la conspiración de Cinadón, fruto de la concentración de la riqueza y la reducción de un gran número de espartiatas a la condición de inferiores o hypomeiones y que pretendió subvertir el orden sociopolítico espartano, acaeció cuando Agesilao no llevaba un año en el trono, como nos dice

76 Pausanias (3.8.3-5) dice también que durante dos años los lacedemonios efectuaron expediciones con la Élide, encabezadas por Agis, y que al comienzo del tercer año los eleos capitularon.

77 Diógenes Laercio (2.9) dice que Fedón estuvo presente en la muerte de Sócrates que tuvo lugar en el mes de Targelión, ca. mayo de 399. Cf. And. 3.15; X. Hell. 4.8.12-16; Pl. Menex. 245 b-c. Si aceptamos que Fedón fue tomado cautivo en Élide uno o dos años antes, es posible que el testimonio de Diógenes acerca de la presencia de Fedón en el momento de la muerte de Sócrates apoye una cronología para las expediciones militares contra la Élide antes de 399.

78 Cf. Cartledge 1987, 353. 
Jenofonte, ${ }^{79}$ ésta habría tenido lugar entre el verano de 399 y el verano de $398 .{ }^{80} \mathrm{En}$ la primavera-verano de 398 caería la expedición espartana en la zona de las Termópilas al mando de Heripidas (Diod. 14.38.4-5).

En relación con Asia Menor, si Agesilao comenzó su actividad militar en esta zona en $396,{ }^{81}$ las dos campañas anteriores, correspondientes a Dercílidas, ocuparían los años 398 y $397^{82}$ y tuvieron lugar una vez que hubo acabado la Guerra de la Élide y no, como quiere Jenofonte (Hell. 3.2.21), en la misma época. La campaña anterior en Asia, la de $399,{ }^{83}$ estuvo mandada por Tibrón, ${ }^{84}$ que, indudablemente, habría llegado a Asia en el otoño de 400, año espartano de 401/0, período en el que realizó, antes de que concluyera la estación para las expediciones militares, una corta campaña con la intención de ganar la orilla derecha del río Meandro al sur de Éfeso. ${ }^{85}$ Parece bastante notorio que Tibrón fue enviado cuando Agesilao no era todavía rey, dada la hostilidad que Jenofonte siente hacia él, por lo que no cabe calificarle precisamente como un partidario de Agesilao, frente a Dercílidas, cuya actuación es alabada por Jenofonte, que fue despachado, en cambio, cuando Agesilao era ya rey y que debía formar parte del círculo de amigos del nuevo diarca. ${ }^{86}$

Tibrón fue enviado como respuesta al regreso de Tisafernes a la Jonia tras el fracaso de la expedición de Ciro, cuando el sátrapa, en el año 400, trató de conseguir que todas las ciudades griegas de Asia obedecieran y pagaran tributo al Gran rey, atacando Cime e intentando apoderarse de Mileto ${ }^{87} \mathrm{El}$ regreso de los mercenarios griegos supervivientes de la expedición de Ciro ocuparía los meses finales de 401 y los primeros de 400 . Entre la primavera y septiembre de 400 los mercenarios estuvieron en Asia Menor y en Tracia ${ }^{88}$ antes de ser empleados por Tibrón. ${ }^{89}$ La expedición de Ciro con la intención de hacerse con el trono persa habría acontecido en 401 con

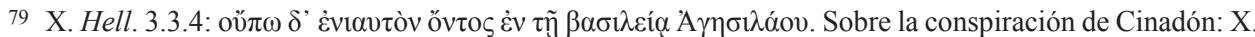
Hell. 3.3.4-11; Polyaen. 2.14.1; David 1979; VATtuOne 1982; LAZENBY 1997; Fornis 2007.

80 Si Jenofonte se refiere al año civil espartano, ésta se fecharía a finales del verano de 399, hacia septiembre, en conexión quizá con el debate sucesorio.

81 Año espartano 397/6. Regresó de Asia en el año espartano 395/4, después de permanecer en la zona a lo largo del año 396/5. Sobre las expediciones militares espartanas en Asia puede verse DeBORD 1999, 234-248; PAscual 2007.

82 Años espartanos 399/8 y 398/7.

83 Año espartano 400/399. X. Hell 3.1.6-7; Cf. también Diod. 14.37.4.

84 X. Hell. 3.1.4; Diod. 14.36.1-2.

85 Diod. 14.36-37; PARETI 1961, 265-268.

86 X. Hell. 3.1.1, 6-8, 10, 3.2.6 (Tibrón); 3.1.10, 16-28; 3.2.1, 9, 11 (Dercílidas); Pascual 2007, 200.

87 X. Hell. 3.1.3; Polyaen. 7.14.2; WestLake 1981, 257-258.

88 Después de la batalla de Cunaxa los mercenarios griegos supervivientes alcanzaron Cotiora (c. abril 400). Cincuenta y cuatro días después están en Trapezunte desde donde Quirísofo va a pedir naves a Anaxibio, que debe ser navarco espartano de 401/0. De vuelta a Cotiora, los Diez Mil están aquí cuarenta y cinco días hasta $c$. mitad de junio, y su estancia en Calpe parece bastante larga, quizá hasta mediados de agosto. Más tarde, atraviesan Bitinia hasta Crisópolis y luego alcanzan Bizancio y pasan a Tracia. En este momento Anaxibio está esperando que llegue su sucesor Polo, navarco de 400/399, por lo que los Diez Mil debían estar en Bizancio hacia septiembre del 400 (vid. X. Anab. 7.2.5-7).

89 X. Hell. 3.1.6; Anab. 7.6.1: Tibrón envió a Cármino y Polínico para tratar de la incorporación de los cireos que se produce en Anab. 8.24 (otoño de 400 o principios de 399). 
un ataque previo de Ciro contra Cilicia en el año anterior, 402. ${ }^{90}$ En este mismo año de 402, los lacedemonios enviaron un ejército bajo el mando del harmosta Pantedas que expulsó a Clearco, el comandante espartano de Bizancio, cuyo comportamiento tiránico sirvió de pretexto para una intervención que debió tener en cuenta más bien el deseo laconio de asegurarse el control de los Estrechos ante una posible revuelta de los bizantinos y ante la conducta demasiado independiente de Clearco. Éste buscó refugio junto a Ciro, que había sido puesto al frente de las satrapías marítimas y que estaba planeando llevar a cabo una expedición contra su hermano Artajerjes para arrebatarle el trono persa. ${ }^{91}$ Finalmente, también en 402, Ciro habría enviado una embajada a Esparta para reclamar su ayuda (X. Hell. 3.1.1-2).

En definitiva, los acontecimientos de los años 403 a 396 en Grecia continental y en Asia Menor quedarían de la manera siguiente (tabla 5):

\begin{tabular}{|l|l|}
\hline Año (juliano) & Acontecimiento \\
\hline 403 & Restauración democrática en Atenas \\
\hline 402 & $\begin{array}{l}\text { Los lacedemonios expulsan a Clearco de Bizancio } \\
\text { Embajadores de Ciro en Esparta } \\
\text { Expedición de Ciro contra Cilicia }\end{array}$ \\
\hline 401 & $\begin{array}{l}\text { Expedición de Ciro para hacerse con el trono persa } \\
\text { Ocupación tebana de Oropo } \\
\text { Anexión ateniense de Eleusis } \\
\text { Primera expedición lacedemonia contra la Élide }\end{array}$ \\
\hline 400 & $\begin{array}{l}\text { Segunda expedición de los lacedemonios contra la Élide } \\
\text { Regreso de los mercenarios griegos } \\
\text { Primera campaña de Tibrón en Asia (finales del verano) }\end{array}$ \\
\hline 399 & $\begin{array}{l}\text { Segunda campaña de Tibrón en Asia } \\
\text { Capitulación de la Élide } \\
\text { Agis en Cefalonia, Naupacto y Delfos } \\
\text { Muerte de Agis II. Agesilao II nuevo rey } \\
\text { Conspiración de Cinadón }\end{array}$ \\
\hline 398 & $\begin{array}{l}\text { Primera expedición de Dercílidas en Asia } \\
\text { Expedición lacedemonia al mando de Heripidas en las Termópilas }\end{array}$ \\
\hline 397 & Segunda campaña de Dercílidas en Asia \\
\hline 396 & Primera campaña de Agesilao en Asia \\
\hline
\end{tabular}

Tabla 5. Los acontecimientos en Grecia continental y Asia Menor entre los años 403 a 396.

90 Libis, el hermano de Lisandro, que interviene en Atenas, es claramente el navarco lacedemonio del año 404/3 (X. Hell. 2.4.28). Después de que los embajadores de Ciro fueran a Esparta, los éforos enviaron al navarco Samio con treinta y cinco barcos, que se unió en Cilicia a los veinticinco barcos de Ciro que venían desde Éfeso bajo el mando de Tamos y cooperaron con él para someter Cilicia (X. Hell. 3.1.1). Cf. Diod. 14.4-5 donde es lla-

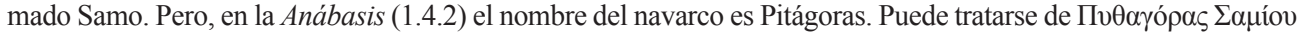

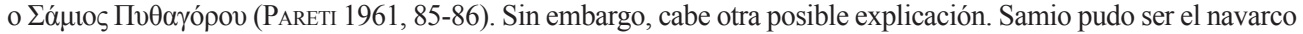
sucesor de Libis entre el verano de 403 y el verano de 402 y Pitágoras el navarco del año siguiente (402/1). Tras el fracaso de la expedición de Ciro, los mercenarios griegos supervivientes se reunieron en Cotiora doscientos once días después de la batalla de Cunaxa, lo que caería, en efecto, c. abril del 400. Cf. X. Anab. 1.2.21, 4.2-3.

91 Diod. 14.12.2-9. 


\section{BIBLIOGRAFÍA}

Alder, W. - Tuffin P. (2002): The Chronography of George Synkellos, translated with introduction and notes, Oxford.

Alonso Troncoso, V. (1987): Neutralidad y neutralismo en la Guerra del Peloponeso (431404 a.C.), Madrid.

BeLoch, K. J. (1921-27): Griechische Geschichte, 8 vols., Estrasburgo - Berlín.

BuCKLer, J. (2003): Aegean Greece in the fourth century BC, Leiden.

Bickermann, E. (1934): "Notes sur la chronologie de la XXX $X^{\mathrm{e}}$ dynastie", Melanges Maspero $1,77-84$.

Bommelaer, J. F. (1981): Lysandre de Sparte. Histoire et traditions, París.

Bresciani, E. (1985): “The Persian Occupation of Egypt”, [en] I. Gershevitch, The Cambridge History of Iran. Vol. 2. The Median and Achaemenid Periods, Cambridge, 502-528.

CARLIER, P. (1984): La royauté en Grèce avant Alexandre, Estrasburgo.

Cartledge, P. (1987): Agesilaos and the Crisis of Sparta, Baltimore.

CARY, M. (1927): “The Ascendancy of Sparta”, [en] S. A. Cook - J. B. Bury - F. E. Adcock - M. P. Charlesworth (eds.), The Cambridge Ancient History, vol. VI, Cambridge, 25-54 [reimpr. 1969].

Chassinat, E. (1932): Le temple d'Edfou, vol. VII. (=Mem. Miss. arch, franc. 24), El Cairo.

Cloché, P. (1968): La restauratión democratique à Athènes en 403 av. J.-C., Roma.

DAvid, E. (1979): “The Conspiracy of Cinadon”, Athenaeum 57, 239-259.

Debord, P. (1999): L'Asie mineure au IV siècle. Pouvoirs et jeux politiques, París.

DeVoto, J. G. (1982): Agesilaos II and the Politics of Sparta, 404-377 B.C., Chicago.

Engsheden, A. (2006): "La parenté des Nectanébo", CdE 81, 62-70.

FALKNER, C. (1996): "Sparta and the Elean War, ca. 401/400 B.C. Revenge or Imperialism?", Phoenix 50, 17-25.

Felber, H. (2002): "Die demotische Chronik", [en] A. Blasius - B. U. Schipper (eds.), Apokalyptik und Ägypten. Eine kritische Analyse der relevanten Texte aud dem griechischrömischen Ägypten (=OLA 107), Lovaina, 65-112.

FORNIS, C.

(2003): Esparta. Historia, sociedad y cultura de un mito historiográfico, Barcelona. (2007): "La Conspiración de Cinadón: ¿Paradigma de resistencia de los dependientes lacedemonios?", Studia Historica (Historia Antigua) 25, 103-115.

Funke, P. (1980): Homónoia und Arche. Athen und die griechische Staatenwelt vom des peloponnesischen Krieges bis zum Königsfrieden (440/3-387/6 v. Chr.), Wiesbaden.

García Iglesias, L. (1990): "La sucesión real en Esparta. Fallas y paliativos de un sistema", Polis 2, 39-51.

Hamilton, C. D.

(1982): "Étude chronologique sur le règne d'Agesilas", Ktèma 7, 281-296.

(1991): Agesilaus and the Failure of Spartan Hegemony, Ithaca - Londres.

Jiménez Fernández, J. - Jiménez Serrano, A. (2008): Manetón. Historia de Egipto, Madrid. Johnson, J. H. (1974): “The Demotic Chronicle as an historical source”, Enchoria 4, 1-17. 
KaEnel, F. von. (1980): "Les mesaventures du conjurateur de Serket, Onnophris et de son tombeau", BSFE 87/8, 31-45.

Kienitz, F. K. (1953): Die politische Geschichte Agyptens vom 7. bis zum 4. Jahrhundert vor der Zeitwende, Berlín.

Koenen, L. (1985): “The Dream of Nektanebos”, BASP 22, 171-194.

Lavagnini, B. (1922): Eroticorum Fragmenta Papyracea, Leipzig.

Lazenby, J. (1997): “The Conspiracy of Cinadon Reconsidered”, Athenaeum 85, 437-447

Leemans, C. (1838): Papyri Graeci Musei antiquarii publici Lugduni Batavi, Lugduni Batavorum.

Lloyd, A. B. (1984): “Egypt, 404-332 B.C.”, [en] D. M. Lewis - J. Boardman - S. Hornblower - M. Ostwald (eds.), The Cambridge Ancient History. Vol. VI. Second edition. The Fourth Century B.C., Cambridge [reimpr. 2006].

Manteuffel, G. (1930): De Opusculis Graecis Aegypti e Papyris, Ostracis Lapidibusque Collectis, Varsovia.

Maspero, G. (1911): Les contes populaires de l'Egypte ancienne, París.

MeEKs, D. (1972): Le grand texte des donations au temple d'Edfou (Bibliotheque d'Étude 59), El Cairo.

Meulenaere, H. DE (1963): "La famille royale des Nectanebo", Z̈̈S 90, 90-93.

Mosshammer, A. A. (1979): The Chronicle of Eusebius and the Greek Chronographic Tradition, Londres. (1984): Georgii Syncelli Ecloga chronographica, Leipzig.

Niese, B.

(1894): “Agesilaos II”, RE 1, 796-804.

(1895): “Archidamos II”, RE 2, 467.

Pareti, L. (1961): Studi minori di Storia Antica, vol. II, Roma.

Perdu, O. (2010): "Saites and Persians (664-332)", [en] A. B. Lloyd (ed.), A Companion to Ancient Egypt, vol. I, Oxford, 140-154.

Pettersson, M. (1992), Cults of Apollo at Sparta. The Hyakinthia, the Gymnopaidiai and the Karneia, Estocolmo.

Pascual, J.

(1997): Grecia en el siglo IV a.C. Del imperialismo espartano a la muerte de Filipo de Macedonia, Madrid.

(2007): "Intervención militar en Asia Menor y política interna en Esparta (404-395 a.C.)", Polis 19, 189-223.

Poralla, P. (1984), A Prosopography of Lacedaemonians from the Earliest Times to the Death of Alexander the Great (Second edition with an Introduction, Addenda and Corrigenda by Dr. Alfred S. Bradford), Chicago.

Richer, N. (1998): Les éphores. Études sur l'histoire et sur l'image de Sparte (VIII'-III' siècles avant Jésus-Christ), París.

Roesch, P. (1982): Etudes béotiennes, París.

RYHOLT, K.

(1998): “A Demotic Version of Nectanebos' Dream (P. Carlsberg 562)”, ZPE 122, 197-200. 
(2002): "Nectanebo's Dream or the Prophecy of Petesis", [en] A. Blasius - B. U. Schipper (eds.), Apokalyptik und Ägypten. Eine kritische Analyse der relevanten Texte aud dem griechisch-römischen Ägypten (=OLA 107), Lovania, 221-242.

SAlmon, P. (1985): “Les relations entre la Perse et l'Egypte du VI e au IV siècle av. J.-C.", [en] E. Lipinski (ed.), The Land of Israel: Cross-roads of Civilizations, (=OLA 19), Lovaina, 147-168.

SAmuel, A. E.

(1962): Ptolemaic Chronology, Munich.

(1972): Greek and Roman Chronology: Calendars and Years in Classical Antiquity, Munich.

Shipley, D. R. (1997): Plutarch's Life of Agesilaos. Response to Sources in the Presentation of Character, Oxford.

SkeAt, T. C. (1954): The Reigns of the Ptolemies, (Munchener Beiträge zur Papyrus-forschung und Antiken Rechtsgeschichte, Heft 39), Munich.

Sмiтh, R. E. (1953/54): “The Opposition to Agesilaus' foreign policy”, Historia 2, 274-288.

SpALINGER, A.

(1992): "The date of the Dream of Nectanebo", SAK 19, 295-304.

(2001): "Calendars", [en] D. B. Redford (ed.), The Oxford Encyclopedia of Ancient Egypt, vol. I., Oxford, 224-227.

Spiegelberg, W. (1914): Die sogenannte demotische Chronik des Pap. 215 der Bibliothèque Nationale zu Paris, Leipzig.

Traunecker, C. (1979): “Essai sur l'histoire de la XXIXe dynastie", BIFAO 79, 395-436.

TRÜMPY, C. (1997): Untersuchungen zu den altgriechischen Monatsnamen und Monatsfolgen, Heidelberg.

Tuplin, Chr. (1993): The Failings of Empire: A Reading of Xenophon Hellenica 2.3.11-7.5.27, Stuttgart.

Underhill, G. E. (1893): “The Chronology of the Elean War”, CR 7, 156-158.

Unz, R. K. (1986): "The Chronology of the Elean War", GRBS 27, 29-42.

VAttuone, R. (1982): "Problemi spartani: la congiura di Cinadone", RSA 12, 19-52.

WadDEll, W. G. (1990): Manetho, Cambridge, MA.

Wallraff, M. (2007): Iulius Africanus: Chronographiae. The Extant Fragments. In collaboration with Umberto Roberto and Karl Pinggéra, William Adler. Die griechischen christlichen Schriftsteller der ersten Jahrhunderte, NF 15. Translated by W. Adler, Berlín - Nueva York.

Westlake, H. D. (1981): “Decline and Fall of Tissaphernes”, Historia 30, 257-279.

WILCKEN, U.

(1905): “Der Traum des Königs Nektonabos”, [en] Mélanges Nicole. Recueil de mémoires de philologie classique et archéologie offferts à Jules Nicole à la occasion du XXXe anniversaire de son professorat, Ginebra, 579-596.

(1927): Urkunden der Ptolomäerzeit, vol. 1, Berlín - Leipzig.

William, A. - Tuffin, P. (2002): The chronography of George Synkellos: a Byzantine chronicle of universal history from the creation, Oxford.

Wissowa, P. (1894): “Agis II”, RE 1, 817-819. 